\title{
Guía para realizar oximetría de pulso en la práctica clínica
}

\author{
SYLVIA PALACIOS M., CECILIA ÁLVAREZ G., PATRICIA SCHÖNFFELDT G., JUAN CÉSPEDES G., \\ MÓNICA GUTIÉRREZ C., MANUEL OYARZÚN G. y COMISIONES DE FUNCIÓN PULMONAR \\ DE ADULTOS Y PEDIÁTRICA, SOCIEDAD CHILENA DE ENFERMEDADES RESPIRATORIAS*
}

\section{Guideline for performing pulse oximetry in the clinical practice}

A brief guideline for carrying out pulse oximetry in the clinical practice is presented. This guideline was written by the Pulmonary Function Commission of the Chilean Respiratory Disease Society. Basic aspects for applying this non-invasive measurement to adults and infants as well as carefulness in interpreting its results are briefly described.

Key words: pulse oximetry; guideline; adults and infants.

\section{Resumen}

Se presenta una guía práctica resumida para efectuar la oximetría de pulso en la práctica clínica. Esta guía fue redactada por la Comisión de Función Pulmonar de la Sociedad Chilena de Enfermedades Respiratorias. Se describen resumidamente los aspectos básicos para aplicar esta medición no invasiva a adultos y a niños y también se consideran las precauciones que se deben tener presente al interpretar los resultados de esta medición.

Palabras clave: Oximetría de pulso, guía práctica, adultos y niños.

La oximetría de pulso $\left(\mathrm{SpO}_{2}\right)$ es la estimación de la saturación arterial de oxígeno $\left(\mathrm{SaO}_{2}\right)$ en forma no invasiva, usando dos emisores de luz y un receptor colocados a través de un lecho capilar pulsátil.

1. Antes de evaluar al paciente se debe probar el funcionamiento del sensor y del equipo realizando una medición en uno mismo. Hay que tener la precaución de utilizar siempre el sensor correspondiente al equipo que se está utilizando y elegir el sensor adecuado al paciente (pediátrico o adulto, para el dedo o para el lóbulo de la oreja).

2. Seleccionar de acuerdo a las condiciones del paciente el sitio donde se colocará el sensor para la medición: lecho ungueal de un dedo de la mano -habitualmente el índice-, en recién nacidos y lactantes se puede utilizar el primer ortejo o el dorso de la mano o del pie; ocasionalmente en adultos se puede utilizar el lóbulo de la oreja.
3. Se debe asegurar que no exista esmalte de uñas, ni otro elemento que pueda interferir como cremas, pinturas, tinturas u otros similares.

4. Siempre se debe colocar el fotodiodo emisor de luz (luz roja) hacia el lecho ungueal y el fotodiodo receptor (que no emite luz) en el extremo totalmente opuesto (en línea paralela) hacia el pulpejo del dedo.

5. Si existe exceso de luz ambiental, se debe cubrir el sensor.

6. Hay que verificar que el sitio de medición se encuentre bien perfundido, no vasocontraído, ni frío, con la piel seca, no sudorosa y evitando cualquier presión sobre el lugar de la medición, por ejemplo manguito de presión.

7. Se deben evitar artefactos de movimiento tratando que el paciente esté lo más tranquilo posible durante la medición, ya sea en posición sentada o en decúbito.

* Comisión de Función Pulmonar de Adultos integrada por los Drs. MT. Beroíza W., G. Borzone T., C. Cartagena S., I. Caviedes S., J. Céspedes G., M. Gutiérrez C, M. Gutiérrez N., R. Moreno B., M. Oyarzún G, y P. Schönffeldt G. Comisión de Función Pulmonar Pediátrica integrada por los Drs. V. Aguirre C., C. Álvarez G., H. Barrientos I., R. Corrales V., AM. Escobar C. y C. Ubilla P. 


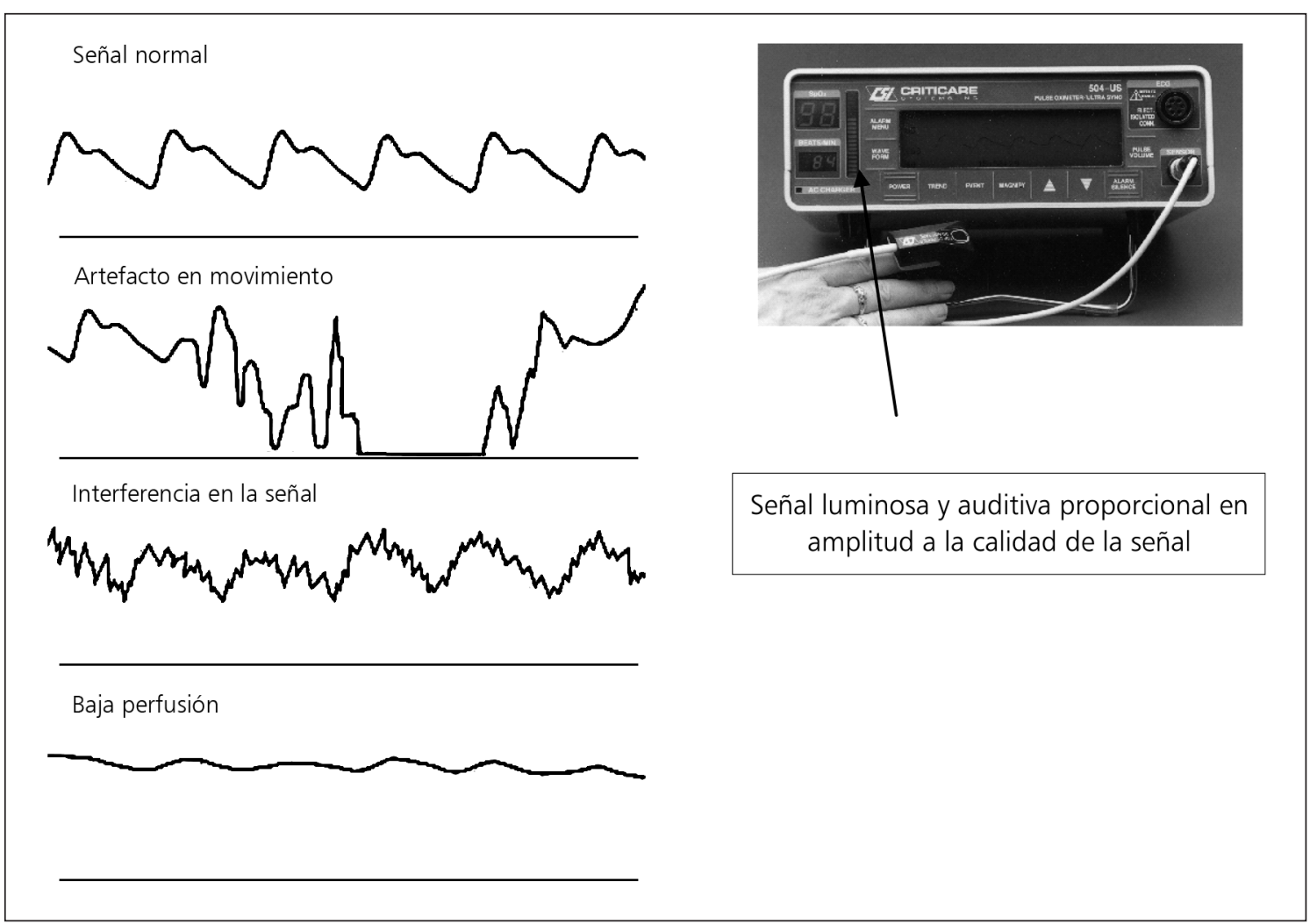

Figura 1. Patrones de curva pletismográfica de la señal de oximetría.

8. Una vez colocado el sensor, se debe evaluar en la pantalla del equipo la estabilidad de la curva pletismográfica o de la señal luminosa, verificando que ésta sea constante en intensidad y en el ritmo, (Figura 1). Cuando existe disparidad entre los valores de la $\mathrm{SpO}_{2}$ y el estado clínico del paciente, o no se logra una buena señal de la curva pletismográfica, hay que cambiar de sitio el sensor y/o probar con otro sensor que se acomode mejor al paciente. Si no se logra corregir el problema no se debe informar la medición de $\mathrm{SpO}_{2}$.

9. Realizar lectura de la saturación y de la frecuencia cardíaca.

10. El informe escrito de los resultados de la medición de $\mathrm{SpO}_{2}$ debe incluir los siguientes datos: a) nombre del paciente; b) fecha y hora en que se realizó el examen; c) fracción inspirada de oxígeno (ambiental o cantidad de suplementación de oxigenoterapia, según el caso); d) modelo y marca del equipo de oximetría de pulso.

11. Se recomienda usar las precauciones universales para la manipulación de los sensores y del equipo.

\section{Precauciones al momento de interpretar la $\mathrm{SpO}_{2}$}

Se debe considerar que existen situaciones y/o condiciones donde la oximetría de pulso puede dar información errónea y no se recomienda su uso; éstas son las siguientes:

1. Valores de $\mathrm{SpO}_{2}<80 \%$ no tienen buena correlación con mediciones por co-oximetria, por lo que se recomienda corroborar estos valores con mediciones de $\mathrm{SaO}_{2}$ a través de gasometría arterial. También hay que considerar que de acuerdo a la curva de disociación de la hemoglobina valores de $\mathrm{SaO}_{2}$ de $100 \%$ no cuantifican el grado de hiperoxemia en pacientes con oxigenoterapia suplementaria.

2. Alteraciones de la hemoglobina:

a. Inhalación de monóxido de carbono (CO) conduce a altos niveles de carboxihemoglobina la cual tiene un coeficiente de absorción de luz similar a la oxihemoglobina, en esta condición el oxímetro de pulso sobreestima el valor de $\mathrm{SpO}_{2}$.

b. En pacientes con sospecha de altos niveles de metahemoglobinemia, que también tiene 
un coeficiente de absorción de luz similar a la oxihemoglobina, el oxímetro de pulso sobreestima el valor de $\mathrm{SpO}_{2}$ (enfermedades congénitas del metabolismo, intoxicación por nitritos, metoclopramida, sulfas, lidocaína, etc).

En estos casos no se recomienda utilizar oxímetro de pulso.

3. Tinturas o pigmentos: El azul de metileno absorbe luz disminuyendo el valor de las mediciones de $\mathrm{SpO}_{2}$. No se ha demostrado que la ictericia afecte la precisión de la $\mathrm{SpO}_{2}$.

4. Baja perfusión: Cualquier causa de baja perfusión (por ejemplo: hipotermia, hipovolemia, enfermedad vascular periférica o shock).

5. Anemia: habitualmente no interfiere si la concentración de hemoglobina es mayor a $5 \mathrm{~g} / \mathrm{dl}$.

6. Pulsación venosa: Un aumento de las pulsaciones venosas secundario a insuficiencia cardíaca derecha, insuficiencia tricuspídea, aumento de presión por torniquete o mangui- to de presión por sobre el sitio del sensor de oximetría, etc, interfiere con las mediciones y conduce a la medición de valores de $\mathrm{SpO}_{2}$ falsamente bajos.

\section{Bibliografías}

1.- AMERICAN ASSOCIATION FOR RESPIRATORY CARE. AARC Clinical Practice guideline: Pulse oximetry. Respir Care 1991; 36: 1406-9.

2.- BICKLER P E, FEINER J R, SEVERINGHAUS J W. Effects of skin pigmentation on pulse oximeter accuracy at low saturation. Anesthesiology 2005; 102: 715-9.

3.- RALSTON A C, WEBB R K, RUNCIMAN W B. Potential errors in pulse oximetry. III: Effects of interferences, dyes, dyshaemoglobins and other pigments. Anaesthesia 1991; 46: 291-5.

4.- TASHIRO C, KOO Y H, FUKUMITSU K, TOMI K, MASHIMO T, YOSHIYA I. Effects of carboxyhemoglobin on pulse oximetry in humans. J Anesth 1988; 2: $36-40$.

Correspondencia a:

Dra. Mónica Gutiérrez Clavería

Coordinadora, Comisión de Función Pulmonar Adultos

Sociedad Chilena de Enfermedades Respiratorias

E-mail:mgancaroe@gmail.com 